\title{
O uso de "novas tecnologias da informação" pelos movimentos sociais e ONGs e o pensamento político de Hannah Arendt
}

\author{
Juliano Tadeu dos Anjos Oliveira ${ }^{1}$
}

\section{Resumo}

O presente artigo tem por objetivo analisar se o uso de 'novas tecnologias da informação', sobretudo da Internet, por ONGs e Movimentos Sociais, é uma ação política entendida conforme pensamento da filósofa alemã Hannah Arendt. Para tal, procura primeiramente discorrer sobre o uso de 'novas tecnologias da informação' pelas ONGs e Movimentos Sociais, a partir da visão de pesquisadores contemporâneos, buscando analisar os impactos do processo de globalização, em especial a ampliação do uso da internet por diferentes atores, para a organização social, política e cultural das sociedades. Num segundo momento, analisa brevemente o modo como uma ONG, a WWF, estabelece-se enquanto Rede e atua em rede através do uso da internet. Finalmente, aborda o conceito de ação política presente no pensamento de Hannah Arendt, pretendendo averiguar se o uso da internet pelas ONGs e Movimentos Sociais enquadra-se neste conceito definido pela pensadora.

Palavras-chave: Internet. ONGs. Movimentos sociais. Ação política. Hannah Arendt.

\section{Introdução}

Nas pesquisas historiográficas e das Ciências Sociais, há uma série de trabalhos que versam sobre os movimentos sociais, buscando analisar as razões e o contexto de seu surgimento, suas principais características e seu modo de atuação, bem como os impactos desta atuação na dinâmica social. Muitos desses trabalhos

\footnotetext{
${ }^{1}$ Graduado em Ciências Sociais, modalidade licenciatura, pela UFMG e Especialista em História, Sociedade e Cidadania pelo UniCEUB. Gestor de Projetos Sociais no Colégio Loyola, em Belo Horizonte.
} 
procuram, também, traçar uma correlação entre as características de determinado movimento social e as teorias de alguns pensadores sociais.

Ao conceber este trabalho, escolhi tratar do tema "Movimentos Sociais e Globalização", sem pretender traçar as características históricas de um movimento social em específico. A preocupação foi perceber como, no horizonte de desenvolvimento das novas tecnologias da informação, ocorrido, sobretudo a partir da década de 1990, se dá a utilização dessas tecnologias pelas ONGs e pelos movimentos sociais (em especial o uso da Internet), e quais são os impactos desses novos canais de participação no exercício da cidadania.

Dentro desse contexto, a pergunta que norteou minhas reflexões foi: o uso das novas tecnologias da informação pelos movimentos sociais e pelas ONGs, em especial estas últimas, é uma ação política, entendida conforme o pensamento político arendtiano?

Nesse sentido, o presente artigo tem por objetivo perceber como elementos e conceitos do pensamento de Hannah Arendt, que discorrem acerca da ação humana, na ênfase dada pela autora à ação política, podem ser identificados na prática dos movimentos sociais e das ONGs que se utilizam da Internet para efetivação de suas ações.

\section{Movimentos sociais, ONGs e o uso da internet}

Um dos impactos do processo de globalização no modo de se organizar a vida política, social e cultural das sociedades, sobretudo a partir dos últimos anos do século XX, deve-se ao desenvolvimento de novas tecnologias da informação, em especial da Internet.

Segundo Ribeiro (2000, p. 470), “[...] a Internet, a rede das redes, atualmente interconecta muitos milhões de pessoas em todo o mundo e tornou-se o mais poderoso meio simbólico, transnacional, de comunicação interativa”. 
Para o sociólogo espanhol Manuel Castells (1999, p. 565), as "Redes constituem a nova morfologia social de nossas sociedades e a difusão da lógica de redes modifica de forma substancial a operação e os resultados dos processos produtivos e de experiência, poder e cultura".

Desse modo, não obstante sua origem estar diretamente ligada ao desenvolvimento de projetos de defesa norte-americanos, o uso da Internet disseminou-se pela sociedade a partir dos anos 90, e provocou um novo modo de configurar o mundo e as relações sociais.

Novamente Castells (1999, p. 441, grifo meu) nos esclarece, ao dizer que:

O processo da formação e difusão da Internet e das redes de $\mathrm{CMC}^{2}$ a ela ligadas nos últimos 25 anos moldou de forma definitiva a estrutura do novo veículo de comunicação na arquitetura da rede, na cultura de seus usuários e nos padrões reais de comunicação. A arquitetura da rede é, e continuará sendo, aberta sob o ponto de vista tecnológico, possibilitando amplo acesso público e limitando seriamente restrições governamentais ou comerciais a esse acesso, embora a desigualdade social se manifeste de maneira poderosa no domínio eletrônico.

Em suma, o ser humano experimentou uma espécie de "encolhimento do mundo", motivado pelo avanço da globalização e pelo desenvolvimento e aumento de intensidade nos processos de comunicação em rede, que interconecta diferentes atores, nas mais distintas partes do mundo, abordando temas e situações de vida que lhes são comuns.

Essas mudanças, segundo Ribeiro (2000, p. 467), colocam-nos no horizonte de uma "comunidade transnacional imaginada-virtual".

A emergência do espaço global fragmentado gera novas relações entre diferentes localidades, a despeito da mediação dos Estados-nações onde elas se situam, e entre estas localidades e o sistema mundial. Novos meios de comunicação, especialmente a Internet, criam, sob a égide

2 Do autor: "Comunicação Global mediada por computadores". 
do capitalismo eletrônico-informático, a possibilidade de existir a comunidade transnacional imaginada-virtual.

Esse conjunto de mudanças que alteraram significativamente as relações, bem como o modo do ser humano colocar-se em relação, tendo fomentado o transnacionalismo, colocaram em pauta na agenda mundial temas transversais que extrapolam os interesses, demandas e reivindicações locais, sendo absorvidos na discussão de Movimentos Sociais e ONGs espalhadas por todo o globo. Para exemplificarmos este processo, propomos algumas considerações acerca da atuação da ONG WWF-Brasil. ${ }^{3}$

\subsection{0 caso WWF-Brasil}

Criada em 1961, na Suíça, a WWF se constitui, hoje como uma rede de organizações, espalhadas por diversas partes do mundo que tem como missão global, segundo seu site institucional:

[...] conter a degradação do meio ambiente e construir um futuro em que o homem viva em harmonia com a natureza através da conservação da diversidade biológica mundial, da garantia da sustentabilidade dos recursos naturais renováveis e da promoção da redução da poluição e do desperdício (WORLD WILDLIFE FUND, 2011).

No Brasil, sua atuação começou em 1971, a partir do apoio a estudos acerca de um primata em risco de extinção na região do Rio de Janeiro, ação que culminou com o desenvolvimento do Programa de Conservação do Mico-Leão-Doura-

\footnotetext{
3 Em 1961, quando foi fundado, a sigla WWF significava World Wildlife Fund o que foi traduzido como Fundo Mundial da Natureza em português. No entanto, com o crescimento da organização ao redor do planeta nas décadas seguintes, a atuação da instituição mudou de foco e as letras passaram a simbolizar o trabalho de conservação da organização de maneira mais ampla. Com isso, a sigla ganhou sua segunda tradução: World Wide Fund For Nature ou Fundo Mundial para a Natureza. Atualmente, porém, a sigla WWF tornou-se tão forte internacionalmente que, para evitar confusão ou mensagens equivocadas, não se faz mais tradução para qualquer significado literal. Ou seja, agora a organização é conhecida simplesmente como WWF, uma organização de conservação global (WORLD WILDLIFE FUND, 2011).
} 
do. Desde então, foram apoiados diversos projetos e pesquisadores brasileiros que tinham como principal foco de atuação a preservação ambiental.

A consolidação do trabalho no país, aliada à necessidade de institucionalização em território brasileiro, levaram à criação da WWF-Brasil, ONG brasileira que passou a integrar a REDE WWF, com 15 anos de atuação no país.

O próprio fato de se constituir como uma Rede de Organizações, de dimensão transnacional, faz com que o uso da Internet seja imprescindível e estratégico para a WWF, possibilitando a interconexão de atores em diversas partes do mundo e a condução de suas ações e projetos.

Através do site da WWF-Brasil, www.wwf.org.br, é possível ao internauta que o visita ter acesso às páginas das WWF em mais de 40 outros países, espalhados pelos cinco continentes, e inteirar-se, desse modo, das ações desenvolvidas em todo o globo. Além disso, ao explorar o site, o internauta se depara com um ícone denominado "Participe", que possibilita ações como a filiação à ONG, a efetivação de doações para projetos, o cadastro para recebimento de informações periódicas, a aquisição de produtos licenciados WWF, dentre outras. É esse tipo de situação que corrobora o que dizíamos na seção anterior, acerca da possibilidade de interconexão de atores diversos em torno de uma causa que lhes é comum e que extrapola o limite do lugar onde se encontram.

$\mathrm{Na}$ efetivação dessas novas formas de participação, presenciamos o desenvolvimento de novas formas de inserção na política e de exercício da cidadania por parte dos movimentos sociais e das ONGs, pois, como foi exemplificado pelo caso WWF, também esses atores passaram a utilizar-se da Internet para se darem a conhecer e para promoverem suas discussões e reivindicações. Para Ribeiro (2000, p. 480),

[...] habituadas ao networking no "espaço físico" e ávidas por meios eficientes de comunicação e informação, as ONGs rapidamente encontraram nas redes eletrônicas um outro meio útil e poderoso para suas necessidades organizativas e políticas. O estabelecimento de redes na política real parece encontrar um espelho ideal nas muitas possibilidades de networking no ciberespaço. Coalizões podem ser feitas com 
vários atores operando em diferentes níveis de agência, comunicações e alianças transnacionais tornam-se efetivas com nenhum ou com pouco controle dos Estados-nações.

Temos, assim, os principais desdobramentos relacionados ao uso das novas tecnologias da informação por parte das organizações da sociedade civil e seus impactos para a sociedade global. Caberia, agora, perguntar-nos se é possível identificar categorias do pensamento de Hannah Arendt, referentes à ação política, nesse novo jogo de relações. Esta é a discussão proposta no próximo item.

\section{Algumas características do pensamento arendtiano presentes no uso de novas tecnologias da informação pelos Movimentos Sociais e ONGs}

\subsection{Breve histórico acerca de Hannah Arendt e seu pensamento}

Ainda que boa parte dos estudiosos de seu pensamento a definam como uma 'filósofa política' e, não obstante, toda sua formação acadêmica ter sido nessa área do saber, Hannah Arendt, em dado momento de sua vida, diz que não é filósofa, mas que o principal objetivo do seu pensamento está em "restituir a dignidade da política”.

Judia alemã e aluna de Heiddeger, Hannah Arendt não só sofreu na pele as mazelas do Holocausto, como não conseguia entender o porquê da adesão de seu mestre ao regime nazista. E foi esse incômodo que a impulsionou a estudar o totalitarismo.

Desse modo, a primeira grande obra de Hannah Arendt é Origens do Totalitarismo (1951), na qual se debruça sobre as causas que levam ao regime totalitário. Em suma, já nesse trabalho, a autora percebe que o totalitarismo (e toda experiência totalitária) é fruto da manipulação das massas, do 'esvaziamento’ do espaço público, sendo este entendido como o local por excelência para o estabelecimento de relações e onde o ser humano cria sentido para sua existência. Tal esvaziamento tem como resultado a falta de sentido e a experiência da banalidade do mal. 
Posteriormente, foi publicado, em 1958, o livro A condição humana, cuja centralidade está na "ação política" e sobre a qual nos debruçaremos, mais pormenorizadamente, no próximo item deste trabalho.

Segundo Lafer (2007, p. 347), as principais ideias presentes em A Condição Humana, têm uma ligação tênue com a discussão travada na obra As Origens do Totalitarismo.

Pois bem: o que é que Hannah Arendt estava tentando compreender em The Human Condition, dos problemas por ela suscitados em The Origins of Totalitarianism? As origens do isolamento e do desenraizamento, sem os quais não se instaura o totalitarismo, entendido como uma nova forma de governo e dominação, baseado na organização burocrática de massas, no terror e na ideologia.

Dada sua formação filosófica, Hannah Arendt recorre constantemente à Filosofia Antiga Grega e, por isso, percebe a experiência da polis como um exemplo privilegiado de lugar onde os homens travam suas relações, criam sentido para sua existência, bem como as condições necessárias para sua convivência e seu 'estar no mundo'.

Do pensamento aristotélico, ela recupera uma definição da natureza humana, a saber: o ser humano é, por natureza, um animal político (zoon politikon).

Por fim, dois conceitos arendtianos fundamentais são encontrados num fragmento de obra publicada postumamente (O que é a política?), a saber: os conceitos de "mundo e política".

Para compreendermos o conceito de "mundo", torna-se necessário recordarmos que 'o ser humano como ser de relações' é algo central no pensamento arendtiano. Desse modo, "mundo" não é o espaço físico, mas sim, "o espaço construído entre os homens, quando se relacionam".

Também o conceito de "política" está intimamente ligado ao fato de o ser humano ser um ser relacional: sendo necessário a ele organizar sua convivência para não viver na condição do caos, dadas as diferenças existentes entre os homens, 
“a política é o que possibilita esta convivência”. Por isso, a ação política está presente e é intrínseca à condição humana.

\subsection{Alguns conceitos arendtianos presentes na obra $A$ condição humana}

O breve histórico acima teve por objetivo uma contextualização do pensamento arendtiano e uma inserção nos principais conceitos que se fazem recorrentes e são fundamentais para compreensão do pensamento da autora. Esses conceitos, juntamente com alguns outros presentes na obra A condição humana, serão fundamentais para uma breve avaliação do uso das novas tecnologias da informação pelos Movimentos Sociais e ONGs.

Em A condição humana, a pensadora pretende debruçar-se sobre as atividades humanas fundamentais (ARENDT, 2007, p. 15):

Com a expressão vita activa, pretendo designar três atividades humanas fundamentais: labor, trabalho e ação. Trata-se de atividades fundamentais porque a cada uma delas corresponde uma das condições básicas mediante as quais a vida foi dada ao homem na Terra.

Após realizar essa definição, passamos a uma análise minuciosa de cada uma dessas atividades humanas, construindo um percurso que atingirá seu ápice na ação política humana.

Em suma, o "labor” é a atividade que está diretamente ligada ao que é essencial para a subsistência humana. É a dimensão biológica, que nos coloca em condição de igualdade com qualquer ser vivo.

O “trabalho" diz respeito à capacidade humana de intervir na natureza, ao domínio de uma techné. Assim sendo, é o que possibilita ao ser humano o domínio da natureza e do mundo. Nas palavras de Arendt (2007, p. 15), “[...] corresponde ao artificialismo da existência humana”. 
Por fim, a "ação" é, segundo Hannah Arendt, a atividade humana por excelência. Nela, o ser humano é efetivamente o animal político (zoon politikon, de Aristóteles), que estabelece relações a fim de criar sentido para sua vida e possibilitar a própria existência. Mais uma vez, recorremos a uma definição dada pela própria pensadora quando enfatiza:

A ação, única atividade que se exerce diretamente entre os homens sem a mediação das coisas ou da matéria, corresponde à condição humana da pluralidade, ao fato de que homens, e não o Homem, vivem na Terra e habitam o mundo. Todos os aspectos da condição humana têm alguma relação com a política; mas esta pluralidade é especificamente $a$ condição - não apenas a conditio sine qua non, mas a conditio per quam - de toda vida política (ARENDT, 2007, p. 15).

Nesse contexto, conceito-chave para se entender a ação política dentro do pensamento arendtiano é o conceito de natalidade, entendida como o potencial humano de inaugurar 'algo novo'.

$\mathrm{Na}$ análise de Lafer (2007, p. 348), este conjunto de conceitos marca toda originalidade do pensamento arendtiano.

Ora, politicamente não existimos isolados, mas coexistimos.

Daí a tensão entre a filosofia - na qual o pensar é a dualidade do diálogo coerente do eu consigo mesmo - e a política, na qual a pluralidade exige um estar sempre ligado aos outros, pois se podemos pensar por conta própria, só podemos agir em conjunto. Esta diferença de postura é a razão pela qual, com poucas exceções (...) os filósofos tendem a ser hostis em relação a toda política. É esta hostilidade que Hannah Arendt elimina, afastando-se da tradição da vita contemplativa ao excluir a mortalidade e ao erigir a natalidade como categoria central da compreensão política.

\subsection{O uso de 'novas tecnologias da informação' pelos movimentos sociais e ONGs e o pensamento político de Hannah Arendt}

O conjunto desses elementos presentes no pensamento arendtiano e revisados brevemente na sessão anterior, permitem-nos avançar para o objetivo propos- 
to neste trabalho, contido na sua introdução, a saber: a relação que se pode estabelecer entre o uso de novas tecnologias da informação pelos Movimentos Sociais e ONGs e as categorias presentes no pensamento político de Hannah Arendt.

Como foi demonstrado ao longo da construção deste trabalho, o ser humano como ser de relações marca o pensamento arendtiano. O ser humano não existe isoladamente, ele coexiste com outros iguais e sua existência é construída cotidianamente por meio das relações que trava consigo mesmo e com o outro.

Nesse sentido, só existimos quando em relação com o outro e mais: quando em relação, mediada pela palavra, criamos juntos sentido para nossa existência.

Como vimos anteriormente, à medida que se utilizam da Internet para partilhar suas ações, os Movimentos Sociais e as ONGs criam uma possibilidade de interação entre indivíduos que se encontram nas mais diversas partes do mundo. Assim, a "Rede" possibilita efetivamente a criação de uma rede, na qual os participantes estão em relação.

Ora, como está claro no pensamento arendtiano, estar em relação é a conditio per quam da ação política, da qual o ser humano não pode se esquivar.

Nesse sentido, o uso da Internet pelas ONGs e Movimentos Sociais, na medida em que estabelece um espaço propício às relações, já tende a se configurar como ação política.

Outro conceito abordado foi o de "mundo", entendido não como espaço físico, mas como espaço onde se dão as relações.

Novamente aqui é possível fazer a correlação entre o uso da Internet e o pensamento arendtiano: se, ao utilizarem da Internet para divulgação de suas ações e para fomentar as discussões em torno das suas reivindicações, os movimentos sociais e ONGs colocam os indivíduos em relação, ainda que essa relação se dê em um ambiente virtual, sem haver um contato direto entre os indivíduos partícipes do processo, tal ambiente virtual pode ser compreendido como um espaço "onde 
se configuram as relações”, sendo então admissível a sua correlação direta com o conceito de "mundo" presente no pensamento de Hannah Arendt.

Em última instância, sendo a "ação" a atividade humana por excelência, na qual o ser humano estabelece as relações e cria sentido para sua existência, no exato momento em que os Movimentos Sociais e as ONGs, seja a partir da sua atuação e fomento à participação in loco, seja a partir das discussões propiciadas via Internet, colocam os indivíduos "em relação“,eles possibilitam a efetivação da “ação” e consolidam aquilo que Hannah Arendt acredita ser próprio da natureza humana: "sermos, eminentemente, animais políticos".

\section{Considerações finais}

Como foi acenado na Introdução do presente trabalho, seu principal objetivo foi analisar, ainda que de modo breve, como elementos e conceitos do pensamento de Hannah Arendt, que discorrem acerca da ação humana, podem ser identificados na prática dos Movimentos Sociais e das ONGs que se utilizam da Internet para efetivação de suas ações.

Na segunda parte do trabalho, em que se discorreu sobre as principais características desse uso da Internet, acreditamos já ter sido possível lançar mão de algumas pistas da presença dos conceitos arendtianos na referida prática.

A terceira parte, dedicada a uma análise mais minuciosa do pensamento arendtiano, pretendeu, em seu percurso, enfatizar alguns aspectos desse pensamento, visto que, dada sua complexidade e vastidão, este só poderia ser mais bem explorado em um trabalho de fôlego. Não obstante tal fator, acreditamos que foram suficientes para o objetivo proposto.

Dado o caminho percorrido, consideramos não ser excessivo afirmar novamente: "somos seres eminentemente políticos". Furtar-nos disso seria colaborar com o que Hannah Arendt mais temia: “o esvaziamento e a falta de sentido". 
O pensamento arendtiano possibilita que nos conscientizemos disso, à medida que nos coloca diante desse horizonte da "responsabilidade pelo outro". Em seu caráter mais profundo e perverso, a falta de sentido é exatamente o total aniquilamento do outro.

Em uma sociedade cada vez mais diversificada, somos convocados, sim, a efetivamente colaborarmos na construção da cidadania, o que demandará de todos a inserção na esfera pública e o reconhecimento pleno do outro.

\section{The use of 'New Information Technologies' by social movements and NGOs related to the political theory of Hannah Arendt}

\section{Abstract}

This article aims to analyze whether the use of 'new information technologies', especially the Internet, by NGOs and Social Movements can be understood as a political action according to the theory of German philosopher Hannah Arendt. In order to do this, it first discusses the use of 'new information technologies' by NGOs and Social Movements from the perspective of contemporary researchers, seeking to analyze the impacts of the globalization process, particularly the expansion of Internet use by different actors, for the social, political and cultural organization of societies. Secondly, it briefly analyzes how a NGO, the WWF, sets up as a network and acts as one through the use of Internet. Finally, it makes an approach to the concept of the political action according to the Hannah Arendt, searching whether the use of Internet by NGOs and Social Movements is related to this Philosopher's concept.

Keywords: Internet. NGOs. Social Movements. Political action. Hannah Arendt. 


\section{Referências}

ARENDT, Hannah. A condição humana. Tradução de Roberto Raposo, posfácio de Celso Lafer. 10. ed. Rio de Janeiro: Forense Universitária, 2007.

ARENDT, Hannah. Origens do Totalitarismo. Anti-semitismo, imperialismo e totalitarismo. Tradução de Roberto Raposo. 5 ed. São Paulo: Companhia das Letras, 1989.

CASTELLS, Manuel. A sociedade em rede. Tradução de Roneide Venâncio Majer. São Paulo: Paz e Terra, 1999.

LAFER, Celso. A política e a condição humana. In: ARENDT, Hannah. A condição humana. Tradução de Roberto Raposo, posfácio de Celso Lafer. 10. ed. Rio de Janeiro: Forense Universitária, 2007.

MUNDO DAS MARCAS. WWF, 2006. Disponível em: <http://mundodasmarcas. blogspot.com/2006/05/wwf-for-living-planet.html>. Acesso em: 26 ago. 2011.

RIBEIRO, Gustavo Lins. Política cibercultural. In: ALVAREZ, Sonia E.; DAGNINO, Evelina; ESCOBAR, Arturo (Org.). Cultura e política nos movimentos sociais latinoamericanos. Novas leituras. Belo Horizonte: UFMG, 2000. p. 465-502.

WORLD WILDLIFE FUND. [Home page], Disponível em: <http://www.wwf.org. br/wwf_brasil/wwf_mundo/wwf/>. Acesso em: 26 ago. 2011. 


\section{Para publicar na revista Universitas Humanas, acesse 0 endereço eletrônico www.publicacoesacademicas.uniceub.br. Observe as normas de publicação, para facilitar e agilizar o trabalho de edição.}

